\title{
Processes of Dynamics of Surface Layers during Low-Amplitude Fretting
}

\author{
Yu. I. Shalapko ${ }^{b}$ and T. V. Tarasova ${ }^{a}$ * \\ ${ }^{a}$ Stankin Moscow State University of Technology, Vadkovskii per. 1, Moscow, 127994 Russia \\ ${ }^{b}$ Khmel'nitskii National University, ul. Institutskaya 11, Khmel'nitskii, 29016 Ukraine \\ *e-mail: tarasova952@mail.ru \\ Received January 17, 2013
}

\begin{abstract}
A model of dynamic effect during low-amplitude oscillations of surfaces comparable with the preliminary displacement and the first acts of sleep under the oscillating tangential loading of the contact is developed. Solving a system of differential force balance equations has yielded the main characteristics of the process of the dynamics of a nominally stationary contact depending on the governing parameters of the system. Regularities of the friction characteristic at low sliding velocity are determined with allowance for the preliminary displacement phenomenon, the Stribeck effect, as well as the parameter of the plasticity and viscosity of friction. The model allows one tracing the evolution of relative displacements and slip velocities, calculating phase diagrams, as well as deriving the friction characteristic and real slip amplitudes typical of the mixed friction mode and low-amplitude fretting.
\end{abstract}

Keywords: nominally stationary joints, fretting, friction characteristic, evolution model, dynamics of third bodies

DOI: $10.3103 / \mathrm{S} 1068366613030124$

\section{INTRODUCTION}

The factor of cyclic relative displacements in the contact is an integral and important essential part of the problem of ensuring the entirety of nominally stationary friction joints (NSFJs). These phenomena have been the object of special studies by many researchers in mathematics, physics, optics, mechanics, and electromechanics. In the beginning of the 20 th century, the tribological aspect of these phenomena was distinguished as an independent conception called "fretting." Since the latter part of the twentieth century, fretting has been purposefully studied as an integral part of the problem of improving the durability and reliability of machine parts. Main efforts were aimed at investigating the nature and regularities of phenomena such as quasistatic friction [1,2], models of the transition from static to kinetic friction [3], specific features of the stick-slip mode [4], the theory of preliminary displacement $[5,6]$, and the dynamics of contact $[7,8]$, as well as developing new methods for surface treatment [9-12], principles of the structural integrity of nominally stationary joints [13], etc. It is clear that, in any case, the relative displacement of the bodies in contact is the most important object of study in many issues related to force interaction, tribochemical activation, time scales, and direct wear during low-amplitude fretting.

The aim of the study is to model relative motion in an oscillating contact with slip.

\section{FOUNDATIONS OF PHYSICAL MODELING OF LOW-AMPLITUDE FRETTING}

The instability of motion is the main specific feature of evolution theories of nonlinear dynamic systems. In the context of fretting processes, the motion or evolution of a system is easily interpreted by determining the relative displacement of two surfaces under the effect of a cyclic tangential load. For low-amplitude fretting, the mode of the relative motion of the surfaces is fairly complex, which is explained by the influence of surface asperities comparable with the amplitudes of microdisplacements, the fits of adhesion activity [15], self-organization mechanisms, the structural dynamics of partial slip [16], microwear [17], plasticity [18], and acts of microslip [19].

The formulation of a boundary problem for differential equations of mathematical physics is the most widespread form of representing a dynamic (evolution) mathematical model of microscale. In these models, time is an independent variable and the phase variables that characterize the state of a system (in our case, the displacements and velocities) are unknown variables. Based on the experience gained, we have proposed a hierarchical model for nominally stationary joints from the viewpoint of the loss of their structural integrity.

Figure 1 shows a four-level system that generalizes the global problem of the integrity of NSFJs. The zero level encompasses the atomic and molecular levels of 
Third level

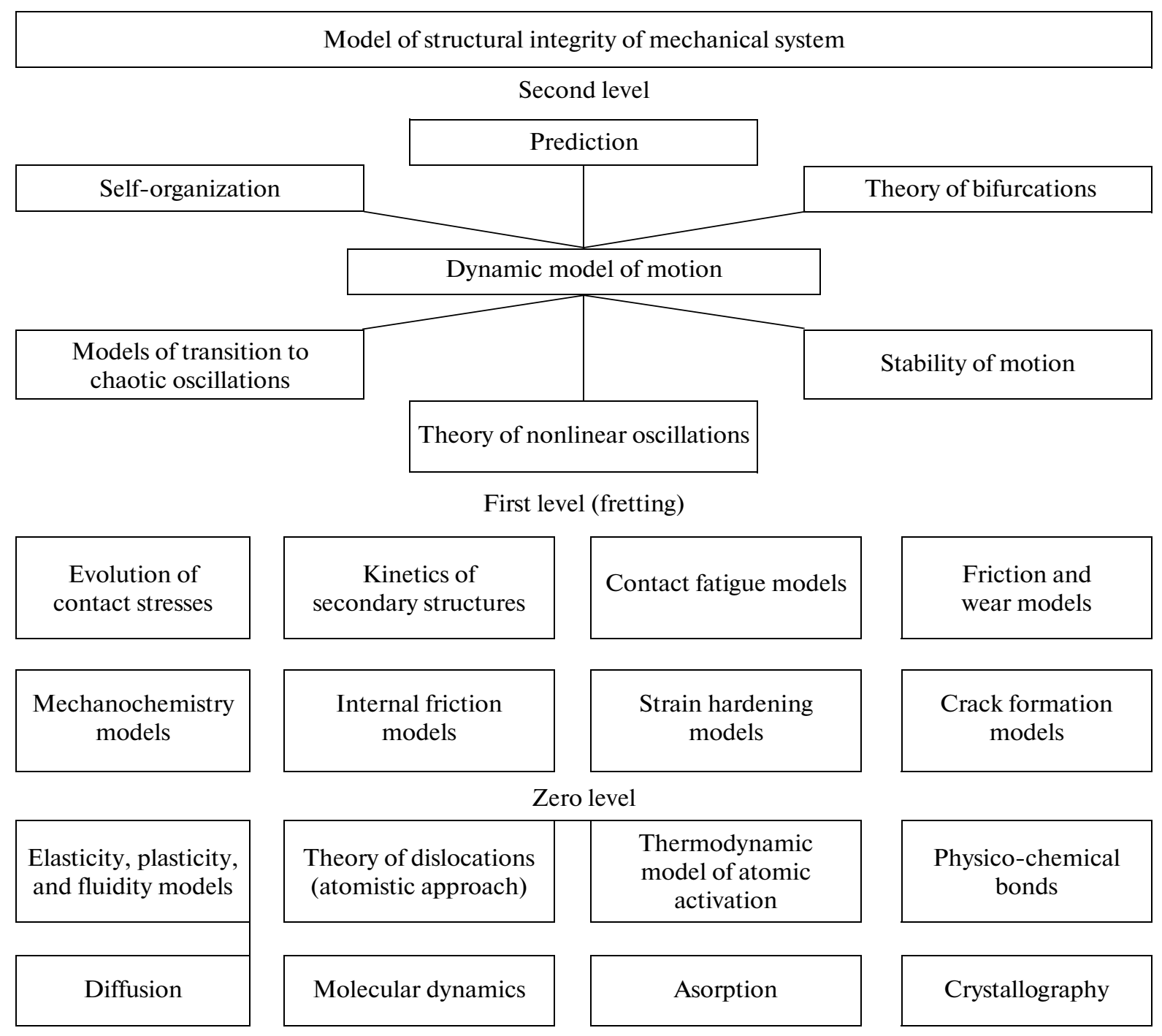

Fig. 1. Hierarchical model of structural integrity of nominally stationary joints.

the structure of matter and its contact interaction. This concerns, first of all, van der Waals interatomic forces, the nucleation, multiplication, and accumulation of dislocations, chemical reactions, etc. The first and second levels can be conventionally classified as the macrolevel, which includes tribological and dynamic phenomena that develop during friction. The relative motion of two surfaces is the source and the compulsory condition of initiating fretting. The initial state of a system is governed by external loading parameters and the physicomechanical properties of surface layers. There are precisely cyclic loading processes and fretting, which lead to the evolution of the motion of a dynamic system towards its loosening and the lost of nominal stationarity; this means transition to the third level of the global model.
The relative motion of two parts governs the pattern of the dynamic behavior of the contact, and the fretting processes are responsible for the integrity of a structure as a whole. Among the more than fifty governing parameters that describe fretting [20], the dynamic parameters of relative slip are the most informative from the viewpoint of criteria of joint serviceability, a possibility of the mathematical processing of oscillograms, diagnostics, prediction, and, most essential, determining the relative displacement. Thus, fretting processes are a motive power of the dynamic motion of a system that consists of two contact surfaces under constant external loading parameters. At some stage, the effect of fretting vanishes and the microdisplacement mode changes into reciprocal friction with an amplitude of more than $50 \mu \mathrm{m}$. The 

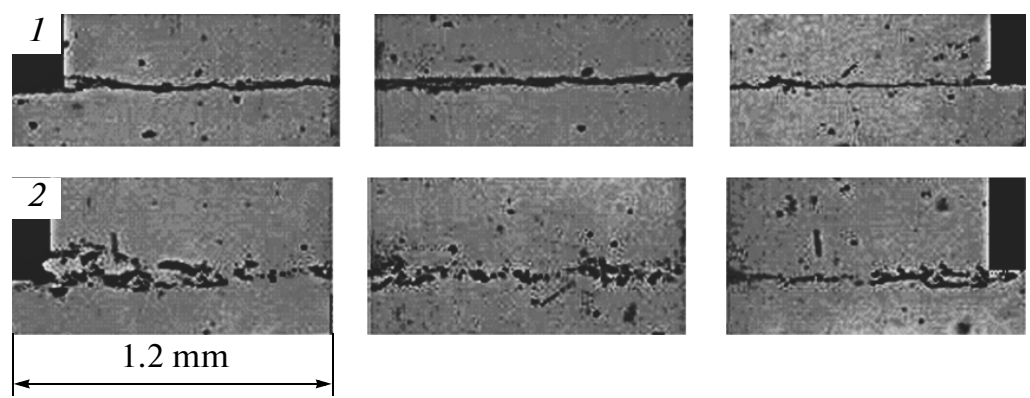

Fig. 2. Degradation of quasistatic contact under cyclic tangential loading. Nominal pressure is $12.6 \mathrm{MPa}$ ( 1 ) number of cycles $N=10^{5} ;(2)$ number of cycles $N=10^{7}$.

dynamic response to the vibrational excitation of the contact is usually identified as the following three modes: stick, partial slip (Mindlin tangential contact), and the global sliding of the surfaces. For a dry contact, these modes are described by an analysis of the following three parameters: the tangential force, the normal load, and the amplitude of the relative displacement.

\section{THIRD BODY CONCEPT FOR MODELING CONTACT MICRODISPLACEMENTS}

The accuracy of determining relative microdisplacements is an essential factor in identifying the dynamics and wear resistance of surface layers under the conditions of low-amplitude fretting. Elastic and plastic deformations of near-contact zones can be comparable with the displacement of two bodies that are recorded by microdisplacement transducers. However, no relative displacement of the surfaces, i.e., sliding friction can occur at all. The second important notion concerns the allowance for mechanical conditions of fastening specimens. Unfortunately, the characteristic of the stiffness of a part or specimen the displacement of which is considered as the amplitude of fretting is not included in the description of up-todate test equipment. The measurement of displacements of one of the two specimens may be useful only

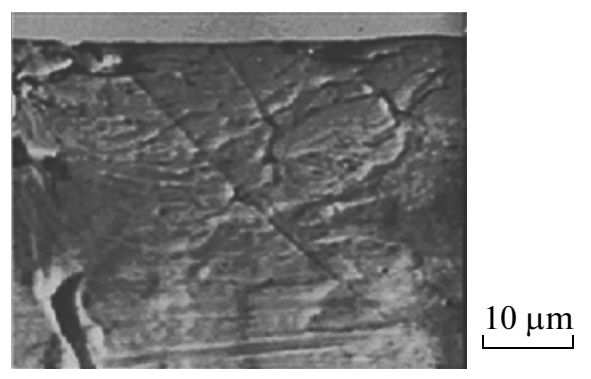

Fig. 3. Fragmentation and formation of movable surface layer during low-amplitude fretting of steel 45: normal pressure is $4 \mathrm{MPa}$ and final slip amplitude is $16.5 \mu \mathrm{m}$. for determining the comparative fretting resistance of various materials. The quantitative and evolution characteristics of a contact pair will be erroneously determined. In addition, the statement of a given amplitude of the relative microdisplacements is not accompanied by a demonstration or analysis of oscillograms of the motion of the upper and bottom specimens. This is the reason of a wide scatter of determining amplitude limits of fretting and the effect of the amplitude on the value of wear.

The study of the contact at small tangential displacements is substantially complicated by the inaccessibility of the interface for the direct measurement of the real microdisplacements of the two surfaces. Only the areas remote from the interface are accessible for measurement. The optical examination of traces of the relative displacement of the surfaces after they have been out of contact offers a real possibility of estimating relative microdisplacements. However, in this case, the elastic component of the contact deformation up to the transition to sliding is not allowed for.

In accordance with the global evolution of a contact during fretting, under cyclic loading, the contact permanently transforms from total stick to slip, which is accompanied by the formation of a third body. Fracture occurs on the periphery of the contact and gradually propagates towards its center (Fig. 2). The fit margin is exhausted due to wear and oxidation, which leads to a transition from static to sliding friction. The study of contact zones has shown that relative motion in the contact is not only the absolute displacement of the bodies, but also the deformation mobility of nearcontact zones (Fig. 3).

Differences in the contact zone and the base material include differences in the elastic modulus, microhardness, mass, and tangential stiffness that do not usually represent the properties of a part as a whole. In the context of dynamic modeling, attention should be focused on both the microdisplacement of the nearcontact zone relative to the counterbody in the case of slip and the cyclic deformation relative to the internal 


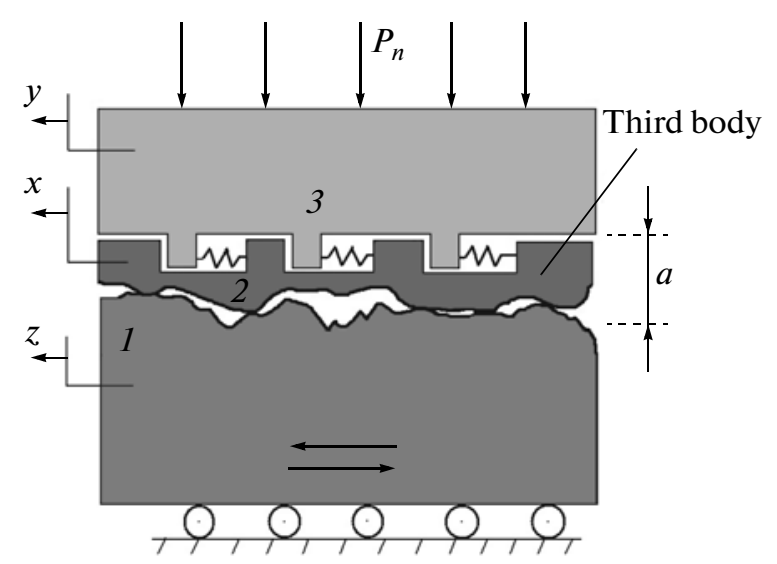

Fig. 4. Concept of nominally stationary friction contact for dynamic model of low-amplitude fretting.

volume of the part as a whole. This concept is schematically shown in Fig. 4.

\section{MATHEMATIC MODELING}

Let us represent the dynamic model of a nominally stationary friction contact (NSFC) as a system of two movable masses $m$ and $M$ (Fig. 5). The mass $m$ is a thin surface layer that is cyclically deformed by friction forces that result from the contact with base 1 . Base 1 harmonically oscillates in the tangential direction and is a source of the kinematic excitation of the system as a whole. When the equations of motion of all components of the model $x(t), y(t)$, and $z(t)$, as well the velocities of these components $\dot{x}(t), \dot{y}(t)$, and $\dot{z}(t)$, have been determined, one can find conditions for real slip between surface 1 and body 3 of the mass $M$.

Macroscopic properties of a third body should characterize all possible microscopic contact phenomena. The third body is interpreted as a whole without specifying its internal structure. In connection with this, the mathematical representation of the contact and the state of the system can be described by a small number of parameters. Unlike the dynamic excitation of one of the bodies by a harmonic force, which is traditionally considered in problems of determining the equations of motion of a dynamic system, this problem is complicated by the uncertainty of the excitation source, i.e., the law of change in the friction force. However, for the fretting process, kinematic excitation is principal from the viewpoint of its classical definition as a tribological phenomenon related to the relative cyclic microdisplacements in the contact of two bodies.

The following notation is used in Fig. 5: $x, y$, and $z$ are the displacements of bodies 1 and 2 of the masses $m$ and $M$, as well as of base 1 , in the stationary system of coordinates, respectively; $c$ is the tangential stiffness; $F_{j}=\mu N$ is the friction force at the moment of time $j ; N$ is the normal force that acts between parts 1

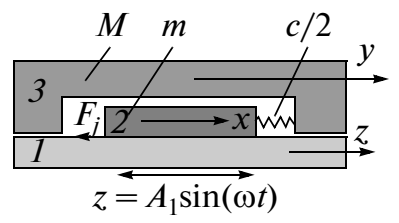

Fig. 5. Schematic diagram of contact and balance of forces applied to contact pair members 2 and 3 during cyclic tangential excitation of base 1 .

and $2 ; \omega$ is the angular frequency of part $1 ; M$ is the mass of part $3 ; m$ is the mass of part $2 ; A_{1}$ is the amplitude of the displacement of part 1 ; and $z=A_{1} \sin (\omega t)$ is the kinematic excitation of base.

We formulate the problem of determining the law of motion of mass $m$ and mass $M$. Let us divide the real time interval from the beginning of motion into equal intervals of the duration $\Delta t=t_{j}-t_{j-1}$, where $t_{j}=t_{0}+j \Delta t$ $(j=1,2,3, \ldots)$. We assume that the time intervals $\Delta t$ are so short that, within each interval, the friction force is considered to be constant. Let $F_{j}$ be the friction force that acts during the $j$ th time interval $\left[t_{j-1} ; t_{j}\right]$. Then, the differential equation that describes the motion of combined NSFCs is as follows:

$$
\left\{\begin{array}{l}
m \ddot{x}=-c(x-y)+F_{j} ; \\
M \ddot{y}=c(x-y) .
\end{array}\right.
$$

The solution of this equation is a fairly intricate problem that is not dealt with in this work. Let us consider the friction characteristic that is the most essential element in the theory of dynamic slip in more detail.

\section{MATHEMATICAL DESCRIPTION OF FRICTION CHARACTERISTICS}

There are a number of interpolation functions of the friction characteristics that, by and large, have no cardinal differences from the mathematical viewpoint, but are of various patterns [21, 22]. In connection with specific features of the relative motion of the surfaces during low-amplitude fretting, we formulated a problem of reproducing analytically such peculiarities of the friction characteristics that were not allowed for in previous studies [23] (Fig. 6).

The notion of the plasticity parameter was introduced by S.G. Kostogryz [24]. The plasticity parameter determines the plastic component of the limiting value of the relative deformation of the contact under direct tangential loading varying from $F=0$ to $F=\mu N$.

It should be noted that the term "relative deformation" has a somewhat different meaning than in the theory of elasticity; it is defined as the ratio of the instantaneous deformation of the contact to the elastic component of the total preliminary displacement. This characteristic determines the plastic component of the total preliminary displacement. The friction 


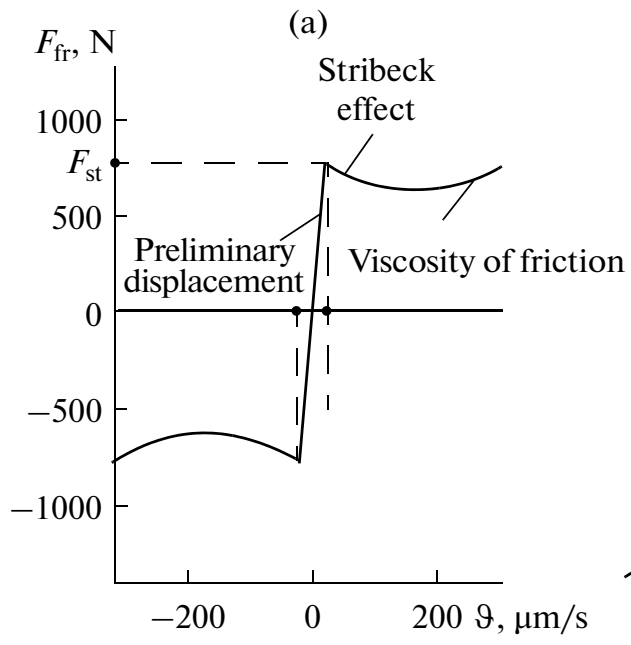

(b)

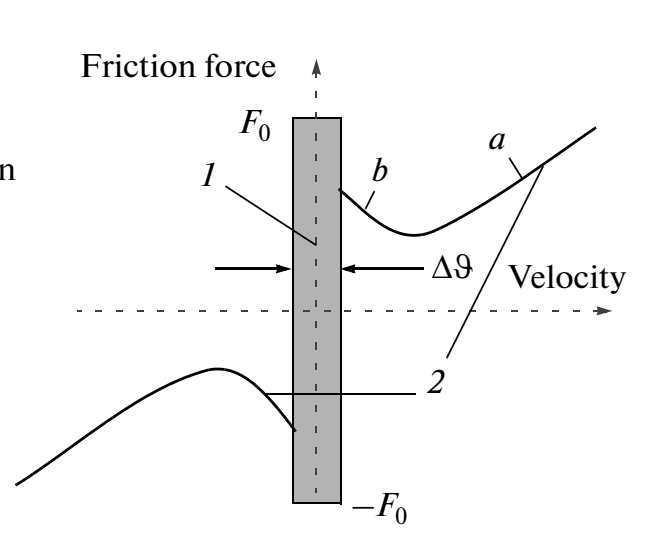

Fig. 6. (a) Characteristics of friction force with allowance for elastic tangential deformation, preliminary displacement, Stribeck effect, and viscosity of friction, as well as (b) graphical explanation of parameters of friction characteristics: (1) stick zone; (2) sliding zone.

(a)

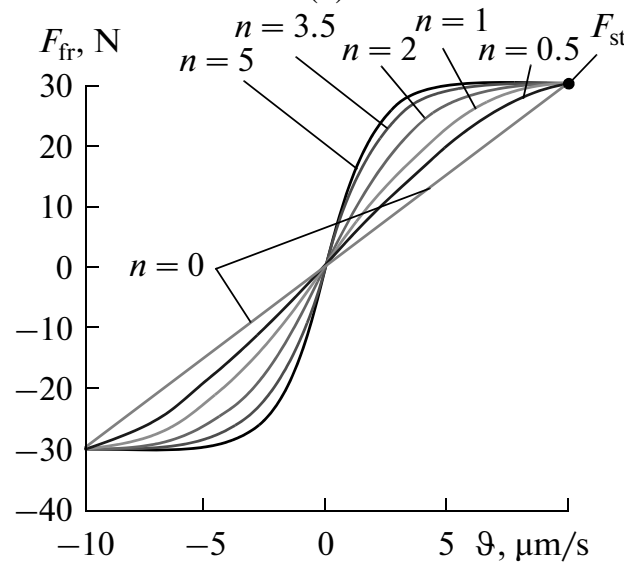

(b)

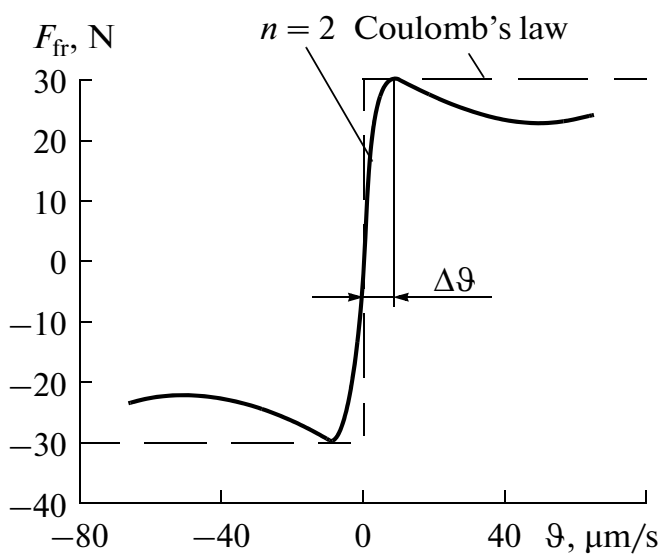

Fig. 7. (a) Friction characteristics within preliminary displacement range at various values of plasticity parameter and (b) general dependence of friction force on relative velocity of displacement and slip of surfaces at $\Delta \vartheta=10 \mu \mathrm{m} / \mathrm{s}, F_{\text {st }}=50 \mathrm{~N}, n=2, a=$ 0.004 , and $b=-0.4$.

characteristics take the form shown in Fig. 7 in accordance with the following analytical expressions:

$$
F(\vartheta)=\left\{\begin{array}{l}
F_{\mathrm{st}}\left[1-\frac{\Delta \vartheta-\vartheta}{\Delta \vartheta}\right]^{\sqrt{n+1}}, \text { at }-\Delta \vartheta<\vartheta<0, \\
\text { preliminary displacement mode, } \\
-F_{\mathrm{st}}\left[1-\frac{\Delta \vartheta-\vartheta}{\Delta \vartheta}\right]^{\sqrt{n+1}}, \text { at }-\Delta \vartheta<\vartheta<0, \\
\text { preliminary displacement mode, } \\
\frac{F_{\mathrm{st}}\left(a \vartheta^{2}+b|\vartheta|+F_{\mathrm{st}}\right)}{a(\Delta \vartheta)^{2}+b|\vartheta|+F_{\mathrm{st}}}, \text { at } \vartheta \geq \Delta \vartheta, \text { slip mode, }
\end{array}\right.
$$

where $a$ is the constant that reflects the ascending portion of viscous friction, $b$ is the constant that reflects the descending portion of the Stribeck effect, $F_{\text {st }}$ is the maximum static friction force, $\Delta \vartheta$ is the velocity of relative displacement below which no slip occurs, and $n$ is the plasticity parameter. The authors of [25] estimated the low velocity limit $\Delta \vartheta$ as $0.1-100 \mu \mathrm{m} / \mathrm{s}$. The parameter $\Delta \vartheta$ depends on the surface quality and deserves special investigation.

\section{MODELING RESULTS}

The following parameters were assumed to be the governing parameters of the model of dynamic motion in the contact: the tangential stiffness $c$ that governed variations in the physicomechanical characteristics of a material and processes of the degradation of a surface layer; the mass $m$ that governed change in the mass of the surface layer that was cyclically deformed 


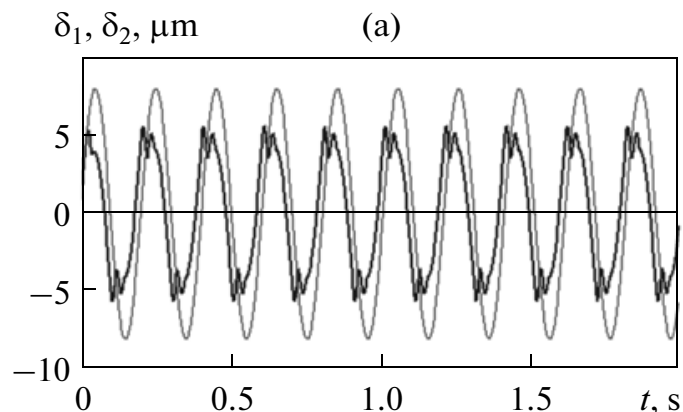

$\vartheta_{0}, \vartheta_{1}, \mu \mathrm{m} / \mathrm{s}$

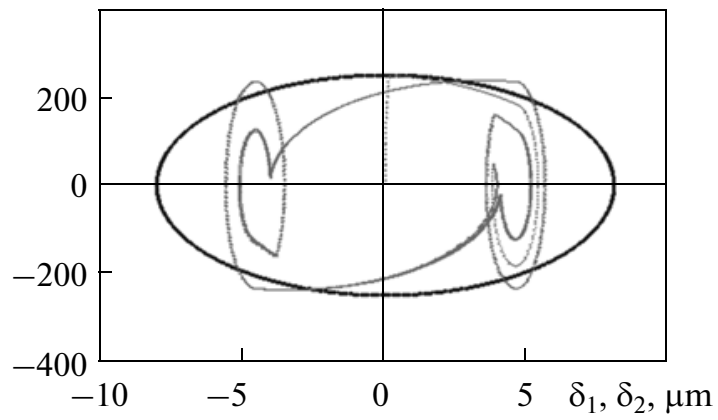

(b)

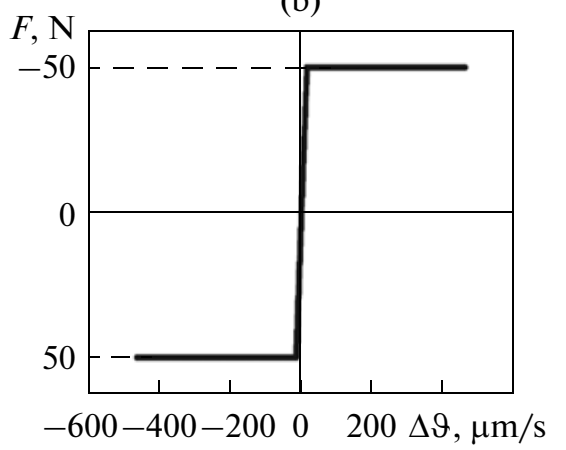

$\vartheta, \mu \mathrm{m} / \mathrm{s}$

(d)

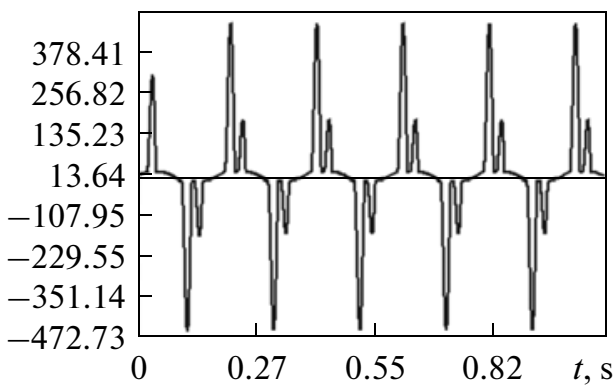

Fig. 8. Characteristics of fretting process obtained on assumption that Amontons-Coulomb law is valid: (a) microdisplacements in contact pair members during harmonic excitation of base; (b) friction characteristics; (c) phase diagram; (d) relative slip velocity.

in the tangential direction and, importantly, modeled the wear process; the friction force; the plasticity parameter $n$; the frequency $\omega$; and the excitation amplitude $A_{1}$. This model makes it possible to assign corresponding laws of time variations in these parameters, thus modeling the staging of the fretting process.

Let us study the influence of the friction characteristic on the pattern of dynamic motion in an NSFC, i.e., the influence of the Stribeck effect and the plasticity parameter. For the Amontons-Coulomb law, the friction characteristics have the coefficients $a=0$ and $b=0$; the plasticity parameter is $n=0$ (Fig. 8). In the case of viscous friction, the friction characteristics consist of only the ascending portion. Vibration activity decreases and the maximum slip velocity is almost halved (Fig. 9d). In transition to slip, the Stribeck effect is most likely to occur for the friction characteristics; its influence on the relative sliding velocity and, thus, on the wear of the surfaces becomes stronger (Fig. 10). It is obvious that the addition of one or two acts of microslip during a single period of oscillations increases the friction component of the stick-slip mode, which affects the fretting resistance and relative mobility of the contact pair. It has been found that an increase in the plasticity parameter leads to the appearance of extra harmonics in the microdisplacements. Under corresponding contact conditions, a moment of transition to global sliding can be determined depending on the process parameters, for example, modeling a natural decrease in the friction force in the contact (Fig. 11).
A gradual decrease in the friction force causes practically instantaneous slip to occur over the whole contact area. The principal distinction of all transient processes is their stepwise behavior. By and large, for critical values of the microdisplacements, the following situation takes place: the loss of the integrity of a contact directly depends on the thickness or mass of an elastically deformed layer, i.e., a decrease in the thickness or mass of this layer sharply increases the slip amplitude. Growth in the frequency of forced oscillations results in the stick of the surfaces. We note however that, at frequencies of $20-100 \mathrm{~Hz}$, the vibrational activity of the contact pair is fairly high, which does not alleviate the problem of fretting resistance for traditional operational frequencies of mechanical systems.

\section{CONCLUSIONS}

A dynamic model of a nominally stationary contact is proposed with an interface that consists of the surface layer of a small mass $m$ and the part base of a mass $M$. The mass $m$ is incorporated into the base through the tangential stiffness. Solving the equations of force balance has yielded time dependences of the main characteristics of the dynamics of the nominally stationary contact at various parameters of the friction characteristics. This model makes it possible to trace the evolution of relative displacements and velocities, calculate phase diagrams, and obtain friction characteristics and slip amplitudes. The regularities of variations in the friction force at low sliding velocities have been deter- 

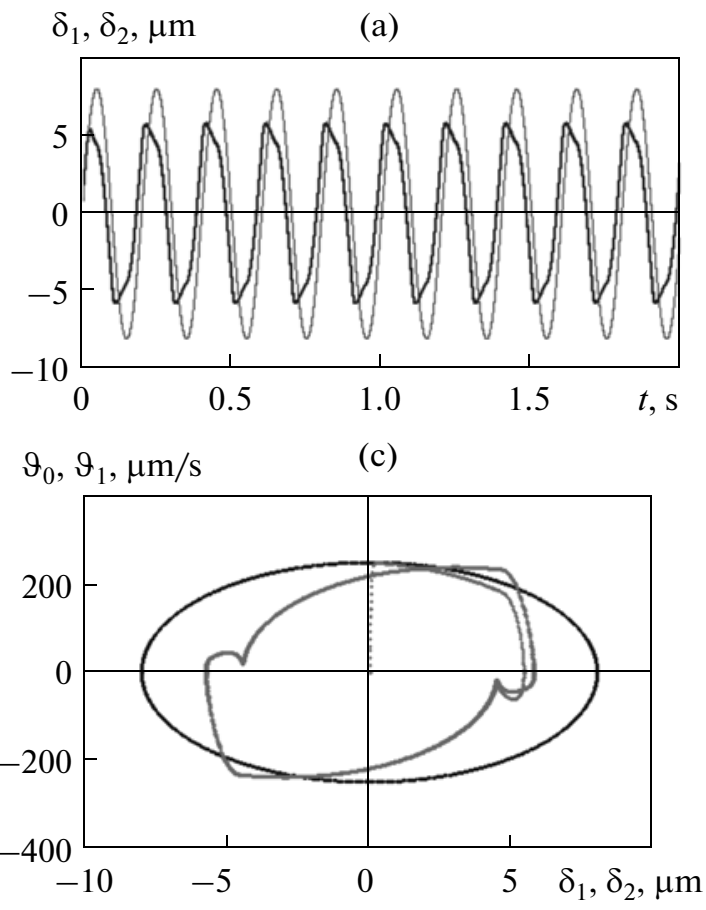

(b)

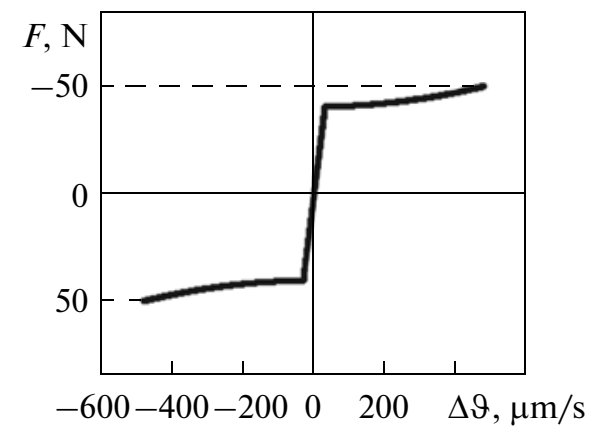

(d)

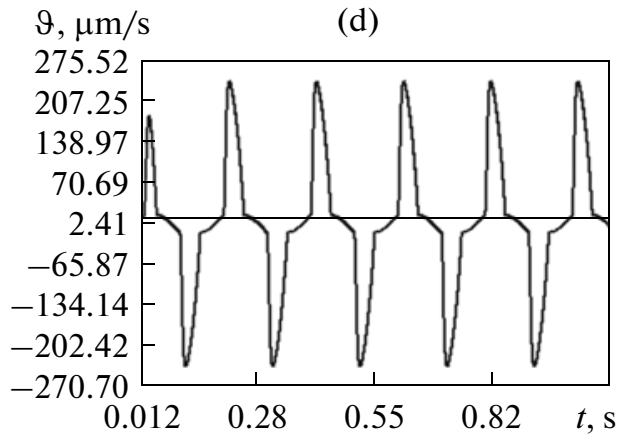

Fig. 9. Characteristics of fretting process obtained under conditions of viscous friction at $a=0.2, b=0$, and $n=0$.

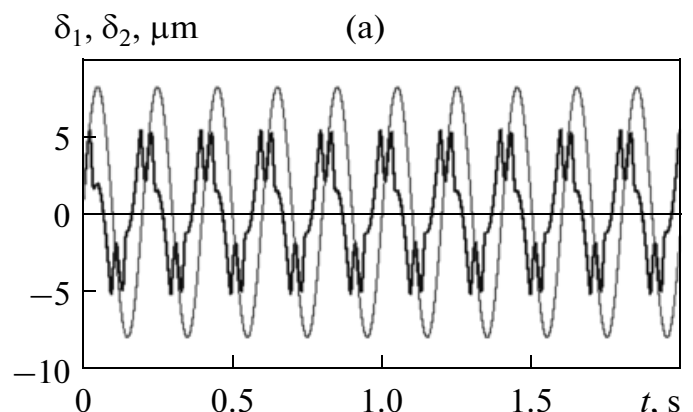

(c)

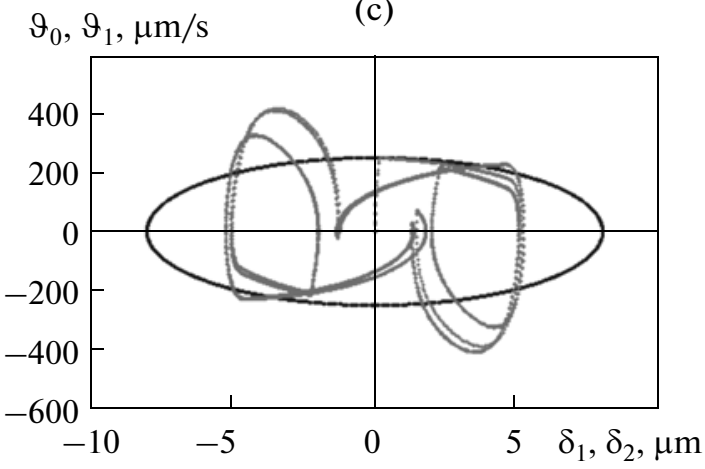

(b)

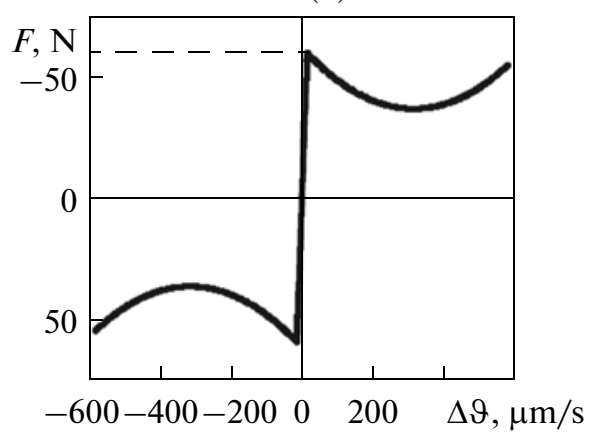

(d)

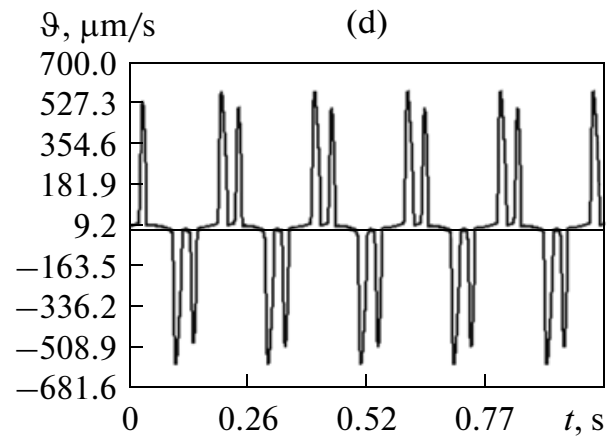

Fig. 10. Characteristics of fretting process obtained under conditions of viscous friction and Stribeck effect at $a=0.2, b=0$, and $n=0$. 


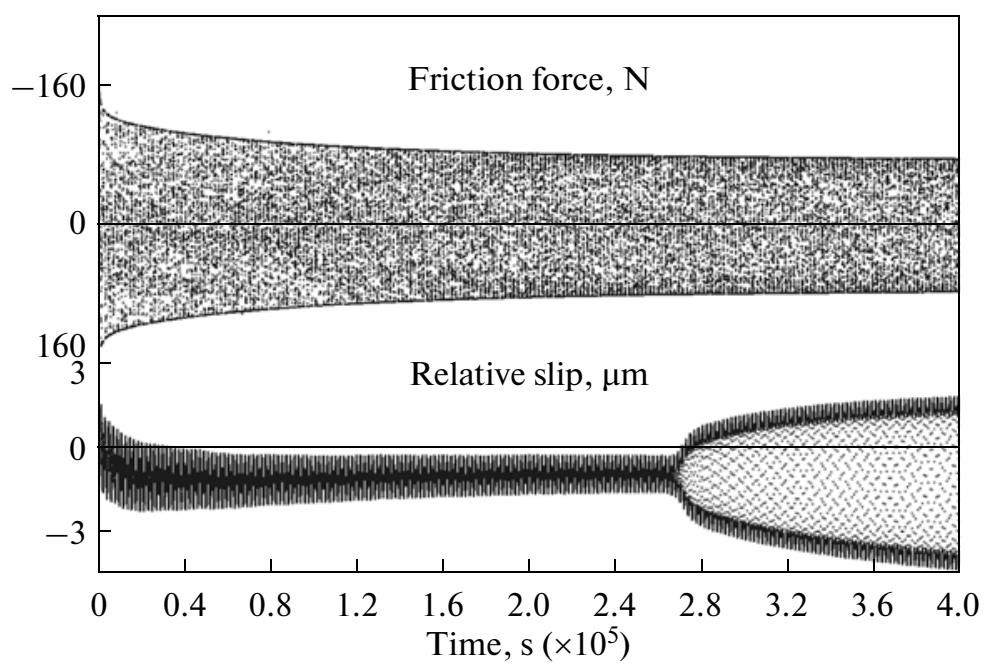

Fig. 11. Long-term evolution of friction force and transition to global slip.

mined with allowance for the preliminary displacement phenomenon, the Stribeck effect, and the viscosity of friction.

\section{ACKNOWLEDGMENTS}

This study was supported by the Ministry of Education and Science of the Russian Federation, Agreement no. 14.B37.21.1841 of October 4, 2012.

\section{REFERENCES}

1. Shillor M., Sofonea M., and Telega J.J., Models and Analysis of Quasistatic Contact: Variational Methods. Lect. Notes Phys., Berlin: Springer-Verlag, 2004.

2. Grigoriev, S.N., Romanov, R.I., and Fominskii, V.Y., Dependence of mechanical and tribological properties of diamond-like carbon coatings on laser deposition conditions and alloying by metals, J. Friction Wear, 2012, vol. 33, pp. 253-259.

3. Ivanov, A.S. and Ermolaev, M.M., Tangent flexibility of rough layer, Izv. Vyssh. Ucheb. Zaved. Mashin., 2012, no. 13 , pp. $23-25$.

4. Shalapko, J. and Kostogryz, S., Evolution of stick-slip regime and chaos for fretting-process, in Proc. 8th Conf. Active Noise and Vibration Control Methods, Krakov, Poland, 2007.

5. Goryacheva, I.G. and Dobychin, M.N., Kontaktnye zadachi $v$ tribologii (Contact Problems in Tribology), Moscow: Mashinostroenie, 1988.

6. Shil'ko, S.V. and Kukhorev, L.P., Method and results of steady state vibration oscillations of mechanical contact. Symmetrical tangential oscillations, J. Friction Wear, 2007, vol. 28, pp. 105-113.

7. Zaspa, Yu.P., Contact resonance in detail joints at vibration. One-dimensional model of non-linear oscillations and its calculation method, Trenie Iznos, 2006, vol. 27, no. 6, pp. 592-611.
8. Zaspa, Yu.P., Razuvaeva, M.A., and Shalapko, Yu.I., Dynamic self-adjustment to external force effect in a nominally stationary friction joint, J. Friction Wear, 2011, vol. 32, pp. 286-290.

9. Tarasova, T.V., Prospects of the use of laser radiation for raising the wear resistance of corrosion-resistant steels, Metal Sci. Heat Treat., 2010, vol. 52, pp. 284-288.

10. Fominskii, V.Yu., Grigoriev, S.N., Gnedovets, A.G., and Romanov, R.I., Specific features of ion-initiated processes during pulsed laser deposition of $\mathrm{MoSe}_{2}$ coatings in pulsed electric fields, Tech. Phys. Lett., 2012, vol. 38 , no. 7, pp. 683-686.

11. Grigoriev, S.N., Romanov, R.I., and Fominskii, V.Yu., Dependence of mechanical and tribological properties of diamond-like carbon coatings on laser deposition conditions and alloying by metals, J. Friction Wear, 2012, vol. 33, no. 4, pp. 253-259.

12. Fominski, V.Yu., Grigoriev, S.N., Gnedovets, A.G., and Romanov, R.I., Pulsed laser deposition of composite $\mathrm{Mo}-\mathrm{Se}-\mathrm{Ni}-\mathrm{C}$ coatings using standard and shadow mask configuration, Surface Coatings Technol., 2012, vol. 206, pp. 5046-5054.

13. Terekhina, M., Malycheva, G., Tarasova, T., Salvia, M., and Fouvry, S., Fretting wear damage of hex-TOOLTM composite depending on the different fiber orientations, in Proc. Bauman's Russian-French Colloq. Young Scientists, Moscow, BMSTU, 2009.

14. Jason, D., Hinkle frictional microslip due to roughness in metallic interfaces at the nanometer scale, Thesis, Univ. Colorado at Boulder, Dep. of Aerospace Eng. Sc., 1998.

15. Kogut, L. and Etsion, I., Adhesion in elastic-plastic spherical microcontact, J. Colloid and Interface Sci., 2003, vol. 261, pp. 372-378.

16. Berger, E.J., Begley, M.R., and Mahajani, Sstructural dynamic effects on interface response formulation and simulation under partial slipping conditions, ASME J. Appl. Mech., 2000, vol. 67, pp. 785-792. 
17. Grigor'ev, S.N. and Volosova, M.A., Nanesenie pokrytii i poverkhnostnaya modifikatsiya instrumenta. Uchebnoe posobie (Infliction of Coatings and Tool Surface Modification. A Textbook), Moscow: ITs MGTU "STANKIN", 2007.

18. Ambrico, J.M. and Begley, M.R., Plasticity in fretting contact, J. Mech. Phys. Solids, 2000, vol. 48, pp. 23912417.

19. Volosova, M.A., Vacuum-plasma technologies: production of nanostructured coatings of tribotechnical and tool destination, Vestnik MGTU "Stankin", 2010, no. 4, pp. 66-73.

20. Beard, J., An investigation in to the mechanism of fretting-fatigue, Ph. D. Thesis, University of Salford, 1982.

21. Sotova, E.S. and Vereshchaka, A.S., Control of contact processes at cutting by functional coating infliction on ceramic tool, Vestnik MGTU "Stankin", 2011, no. 2, pp. 61-67.
22. Grigor'ev, S.N., Kulish, S.M., Zotov, E.A., Solomakho, G.I., and Oshurko, V.B., Effect of friction coefficient decreasing in 'hot' points of friction interface, Estestv. Tekhn. Nauki, 2011, no. 6, pp. 337-343.

23. Baumberger, T. and Caroli, C., Solid friction from stick-slip down to pinning and aging, Adv. Phys., 2006, vol. 55, pp. 279-348.

24. Kostogryz, S.G. and Gladkii, Ya.N., Mathematical simulation of preliminary sliding in nominally immobile friction contact, Problemy Tribologii, 1996, no. 1, pp. 5-15.

25. Kragel'skii, I.V. and Gitis, N.V., Friktsionnye avtokolebaniya (Friction Auto-Oscillations), Moscow: Mashinostroenie, 1987.

Translated by D. Tkachuk 